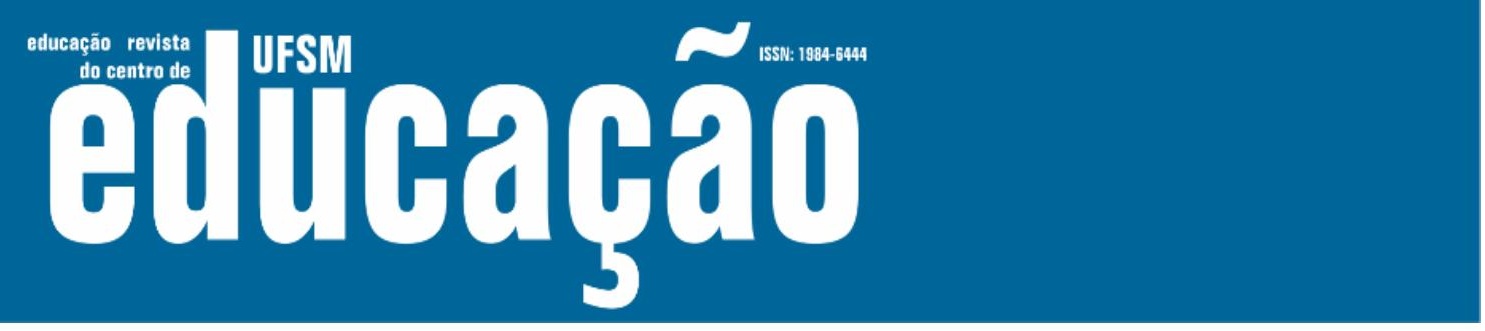

ISSN: 1984-6444 | http://dx.doi.org/10.5902/1984644443774

\title{
Um diálogo entre Bilinguismo, Legislação e Educação Inclusiva no Brasil
}

\section{A Dialogue among Bilingualism, Legislation and Inclusive Education in Brazil}

Janaína Moreira Pacheco De Souza

Professora doutora na Universidade do Estado do Rio de Janeiro. Rio de Janeiro, Rio de Janeiro, Brasil.

janamoreira91@gmail.com - https://orcid.org/0000-0002-3826-7144

Luiz Antonio Gomes Senna

Professor doutor na Universidade do Estado do Rio de Janeiro. Rio de Janeiro, Rio de Janeiro, Brasil. luizagsenna@gmail.com - https://orcid.org/0000-000b2-1086-8829

Recebido em 24 de abril de 2020

Aprovado em 04 de março de 2021

Publicado em 04 de novembro de 2021

\section{RESUMO}

O presente estudo se ancora em reflexões pertencentes à tese de doutorado "Ser professora em área de fronteira bilíngue no Brasil: desafios e possibilidades", a qual discorre sobre as questões pedagógicas que envolvem a inclusão de imigrantes nas escolas de fronteira brasileira. Neste artigo, faremos um recorte da temática apresentada na tese, com o propósito de sinalizar a importância de compreender as questões políticas que direcionaram o processo de ensino e aprendizagem de imigrantes em nossas escolas ao longo dos anos. Nosso intuito é demonstrar que esses alunos sempre estiveram presentes em nosso convívio social e educacional, porém poucas foram as propostas que lhes possibilitaram uma efetiva inclusão educacional. Como aportes teóricos para discutir essas questões, pautamo-nos em documentos oficiais como: Constituição Federal de 1988; Lei de Diretrizes e Bases da Educação Nacional (LDB), Lei n. 9.394, de 20 de dezembro de 1996; Lei no 10.436 do ano de 2002, que dispõe sobre a Língua Brasileira de Sinais - LIBRAS; Estatuto da Pessoa com Deficiência (Lei no 13.146); Estatuto do Estrangeiro (Lei n.으 6.815/80); Lei de Migração (Lei no 13.445/17); na Declaração de Incheon (2015) e em pesquisadores da área da linguística e da educação que reconhecem a necessidade de reflexões pontuais para atender às peculiaridades sociolinguísticas existentes num país de tanta diversidade como o Brasil.

Palavras-chave: Política linguística; Bilinguismo; Inclusão de imigrantes. 


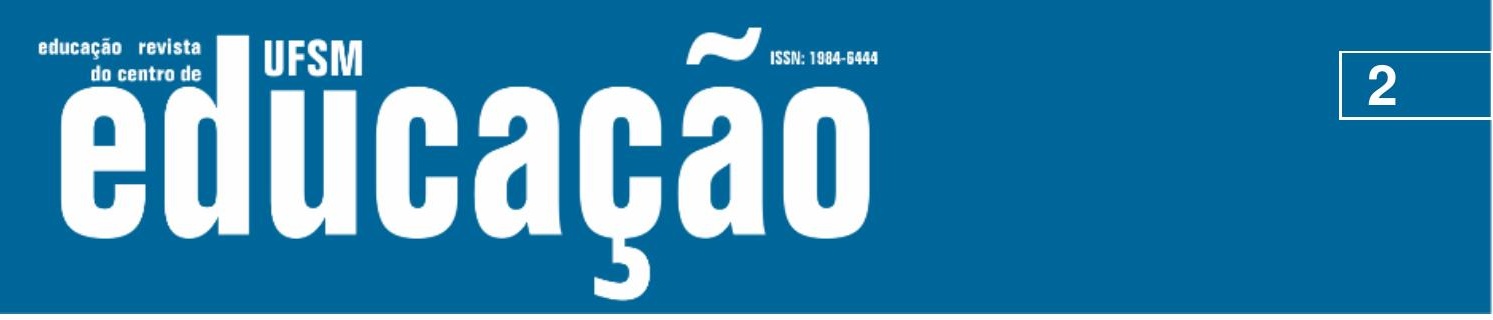

ISSN: 1984-6444 | http://dx.doi.org/10.5902/1984644443774

\section{ABSTRACT}

The present study bases itself in debates that belong to the PhD thesis "Ser Professora em área de fronteira bilíngue no Brasil: Desafios e possibilidades", which expatiates on pedagogical issues that involve the immigrants at schools in Brazilian borders. In this article, we will be doing a cutout on the theme presented in the thesis, with the purpose of signalizing the significance of understanding the political matters that directed the teaching and learning process of immigrants at our schools throughout the years. Our idea is to demonstrate that these students have always been presents in our social and educational interaction; however, few were the politic-pedagogical proposals that made possible a real education inclusion. As theoretical inputs to debate these issues, we based ourselves in official documents as: Federal Constitution of 1988; Law of National Education Guidelines and Bases, law no 9,394, December 20th 1996; law no 10,436 of 2002, that disposes about the Brazilian Signal Language (LIBRAS); Statute of Person with Disability (law no 13,146); Foreigner Statute (law no 6,815/80); law of migration (law no 13,445/17); Incheon Declaration (2015) and researchers on the linguistic and education areas who recognize the need of specific debates to fulfill the sociolinguistics peculiarities existents in a country with so many diversities like Brazil.

Keywords: Linguistic politics; Bilingualism; Immigrants inclusion.

\section{O contexto educacional de imigrantes no Brasil}

Sabemos que a história da imigração se confunde com a própria história do povo brasileiro, marcada inicialmente pela colonização dos portugueses; posteriormente, pela chegada de imigrantes que vieram trabalhar nas lavouras de açúcar e café e, mais recentemente, com um cenário globalizado, assinalado por pessoas de diferentes lugares do mundo, sendo elas legalizadas ou não, mas que têm como um objetivo maior conseguirem uma ascensão na vida, em busca de um melhor emprego, oportunidade de uma vida digna ou fuga de perigos.

Esses sujeitos que sempre estiveram presentes em nossa sociedade e nas escolas brasileiras ganharam tratamentos diferenciados, dependendo da época e do local onde residiam. Na região Sul do Brasil, no início do século XIX, vários grupos que aqui chegaram tinham a intenção de manter sua própria língua e cultura vivas, por isso, optaram por deixar seus filhos em escolas que pudessem contemplar essas questões, porém a legislação brasileira não permitiu que isso acontecesse. 


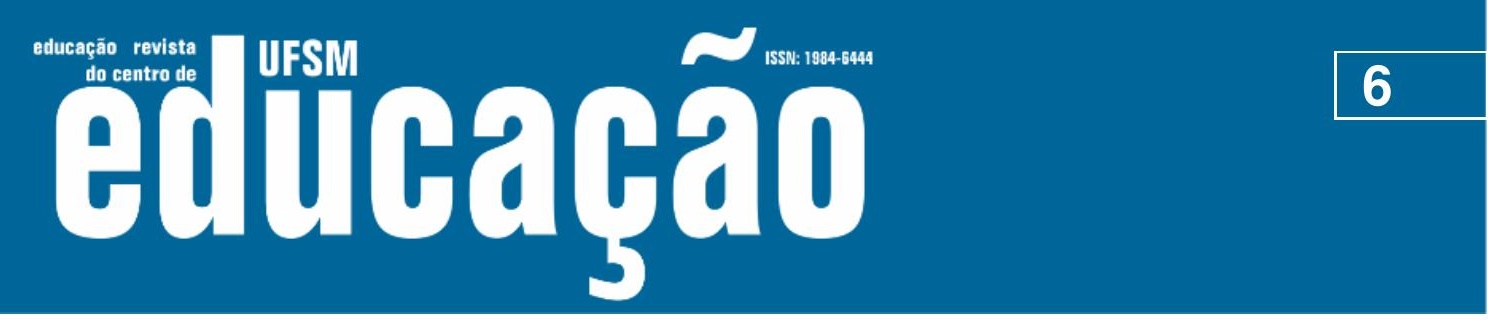

ISSN: 1984-6444 | http://dx.doi.org/10.5902/1984644443774

nível da educação secundária" (DECLARAÇÃO DE INCHEON, 2015) estão fora da escola.

\section{A educação como um direito humano fundamental}

Tendo em vista essa realidade não só no Brasil, mas em diversos lugares do mundo, a ONU aprovou, em 1966, o Pacto Internacional sobre os Direitos Civis e Políticos - Decreto número 592/92 - e o Pacto Internacional sobre os Direitos Econômicos, Sociais e Culturais - Decreto número 591/92, os quais apresentam disposições específicas sobre o tema das minorias étnicas. Esses pactos procuraram integrar os direitos culturais ao rol dos direitos humanos.

$\mathrm{O}$ artigo $27^{\circ}$ do Pacto Internacional sobre os Direitos Civis e Políticos estabelece que:

[n]os Estados em que haja minorias étnicas, religiosas ou linguísticas, as pessoas pertencentes a essas minorias não poderão ser privadas do direito de ter, conjuntamente com outros membros de seu grupo, sua própria vida cultural, de professar e praticar sua própria religião e usar a sua própria língua. (tradução nossa).

A partir dos anos 1970, o corpo de normas sobre os quais se baseia os direitos humanos assume uma maior consistência, exigindo dos Estados o cumprimento de compromissos assumidos em pactos internacionais. Porém, ainda há disparidades a serem superadas entre o que diz a legislação, as práticas escolares estabelecidas nas escolas e a necessidade de uma nova visão para educação inclusiva. A fim de alcançar as metas de universalização dos direitos humanos que inclui as minorias sociais, linguísticas e étnicas, muitas reflexões estão sendo promovidas pelo mundo afora (SABOIA, 1999).

Nesse contexto, destacamos o movimento global Educação para Todos, iniciado em Jomtien, em 1990, e reiterado em Dakar, em 2000, o qual ajudou a promover progressos significativos na educação no que tange à inclusão. E, mais recentemente, em maio de 2015, aconteceu em Incheon, na Coreia do Sul, a convite da Organização das Nações Unidas para a Educação, a Ciência e a Cultura (UNESCO), o Fórum Mundial de Educação. A UNESCO, junto com o Fundo das 


\section{$\sim$ ussm,

ISSN: 1984-6444 | http://dx.doi.org/10.5902/1984644443774

A diversidade como diversificação no ensino de LEs já estava presente no currículo de $5^{\underline{a}}$ e $6^{\underline{a}}$ séries (inglês e espanhol) e nas $7^{\text {a }}$ e $8^{\text {a }}$ séries (inglês, espanhol, alemão e francês). Entretanto, isto não é o suficiente; a diversificação de línguas não garante uma educação para a diversidade, pois não há um trabalho integrado entre as LEs que é um dos aspectos a serem considerados numa educação plurilinguística (para a DL), que busca o desenvolvimento de uma competência plurilíngue e cultural $(\mathrm{BROCH}$, 2012, p. 110).

Para começar a pensar sobre esse paradoxo, necessariamente, temos que discutir a urgência de criar condições que supram a exclusão linguística de muitos alunos matriculados em escolas de fronteira. Esses problemas surgem e, muitas vezes, são ignorados, pela ausência de políticas educacionais e por falsas crenças metodológicas, tais como, acreditar que esquecer ou abandonar uma língua seja a melhor forma de aprender o português (BAKER, 2001).

No entanto, essa complexidade se torna maior quando questionamos algumas situações: como não impedir os alunos de usarem sua própria língua na sala de aula, se o professor não consegue entender o que eles dizem ou se a escola não consegue promover meios para fazer essa integração? Por que as políticas educacionais não avançam nas discussões sobre os reais problemas das escolas? Por que os currículos acadêmicos têm andado a passos lentos no que se refere às necessidades de regiões em que o bilinguismo é fator naturalizado pela comunidade?

Refletir sobre essas indagações talvez nos faça pensar sobre o fato de que, ainda hoje, estamos perpetuando a mesma política nacionalista que extinguiu as escolas de imigração, que proibiu professores que não fossem brasileiros atuarem, que queimou arquivos que não estavam apropriados para o ensino da língua portuguesa, que massifica o que não está de acordo com o interesse de um grupo. Ou seja, ainda estamos contribuindo para que haja discriminação daqueles que não são falantes da língua portuguesa padrão, conforme aponta Faraco (2002). 


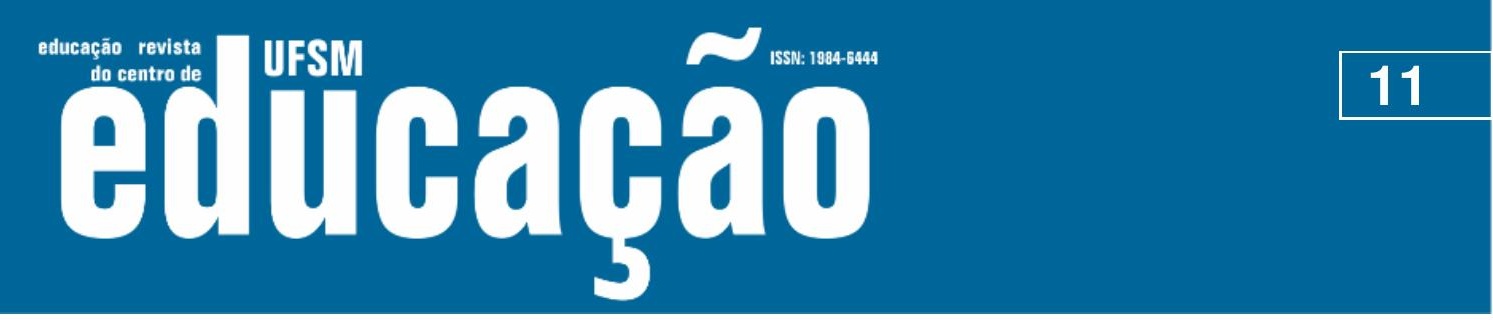

ISSN: 1984-6444 | http://dx.doi.org/10.5902/1984644443774

O desafio é criar condições para uma crítica da atitude normativista, de modo a favorecer a criação de um novo patamar conceitual que permita o rompimento, no ensino e no uso padrão, das amarras que hoje impedem sua apropriação como bem cultural pelo conjunto da população. E essa não é uma tarefa apenas para especialistas, porque ela é, de fato de natureza política. Só um debate público, amplo e irrestrito, poderá desencadear o processo de necessário redesenho do padrão e da cultura linguística do país (p. 38).

Oliveira (2015, p. 23) reitera que essa discriminação linguística no Brasil também acontece porque "não há legislação específica que disponha sobre os crimes de práticas de exclusão das minorias pelo não domínio da língua portuguesa". Portanto, abrir esse diálogo entre o que está previsto em Lei e o que realmente acontece nos contextos escolares pautados pela diversidade sociolinguística, é de extrema importância para que possamos observar como se configura um cenário que se ancora em preconceitos. O reconhecimento desse tipo de discussão abre espaço para possíveis implementações de ações que favoreçam políticas de inclusão em nosso país.

\section{A diversidade linguística brasileira}

A imagem de um Brasil monolíngue é paradoxal à nossa história, pois quando os portugueses desembarcaram em território brasileiro, aqui já se falavam cerca de 1.270 línguas, ou seja, desde a colonização somos formados pelo entrecruzamento de línguas, de diversas raças e crenças - o que faz de nossa identidade pluriétnica (OLIVEIRA, 2015). O cenário linguístico brasileiro é heterogêneo e complexo, apesar dessa falsa imagem monolíngue absorvida pela sociedade e pelas instituições educacionais que perpetuam a crença de que todos devem aprender a língua portuguesa nos mesmos moldes, seguindo a mesma metodologia, como se ela fosse a língua materna de todos que vivem aqui.

Segundo o Instituto Brasileiro de Geografia e Estatística (IBGE, 2010), existem cerca de 330 línguas, sendo 274 indígenas e 50 línguas de imigração. Além dessas, há a presença da Língua Brasileira de Sinais (LIBRAS), cujo ensino já se tornou obrigatório em vários cursos de graduação no país, e dos dialetos afrodescendentes que abrangem todo o território nacional. 


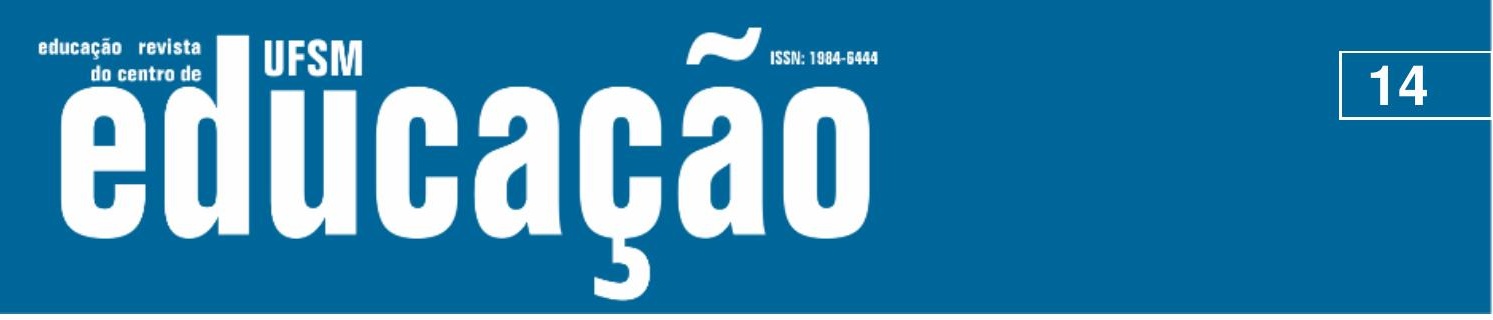

ISSN: 1984-6444 | http://dx.doi.org/10.5902/1984644443774

educação de um país deveria ser uma necessidade, segundo Hornberger e Mckay (2010, p. 15), pois:

[a]s salas de aula multiculturais e multilíngues estão se tornando a regra e não a exceção. [...] o crescimento de pesquisas no campo da sociolinguística tem levado a novas áreas de especialização, por exemplo, conscientização linguística crítica, multiletramentos e socialização linguística, juntamente com áreas mais distantes, tais como planejamento linguístico, multilinguismo e variação transcultural nos usos da linguagem, cada um com sua própria visão de como a linguagem e a sociedade interagem. (tradução autoral)

Com base nessas reflexões, serão apresentados fragmentos de estudos documentais e bibliográficos com o objetivo de analisar as políticas linguísticas explicitadas na Constituição Federal de 1988 (BRASIL, 1988); na Lei de Diretrizes e Bases da Educação Nacional (LDB), na Lei n. ${ }^{\circ}$ 9.394, de 20 de dezembro de 1996 (BRASIL, 1996), na Lei nํㅜ 10.436 do ano de 2002 e na Lei $n^{\circ} 13.146$ de 2015. Essa abordagem trará à tona a realidade de alguns municípios brasileiros habitados por um número expressivo de imigrantes que frequentam escolas brasileiras e aprendem o português como se fosse a primeira língua. Alguns, através de muitas discussões e persistência, conseguiram legalizar o processo de cooficialização de línguas, outros ainda sofrem por essa ausência de políticas, o que acaba afetando a formação cidadã desses indivíduos. Visualizaremos, ainda, através dessa reflexão, os aspectos que amparam a questão indígena no Brasil e o avanço do processo de legitimação das LIBRAS em nosso território.

\section{A legislação brasileira referente ao bilinguismo}

A Constituição Federal, que é o principal documento utilizado pelo Brasil para resolver questões jurídicas e políticas, começa a sinalizar, a partir de 1988, um reconhecimento dos direitos culturais e linguísticos que viabilize o bilinguismo e o multiculturalismo no território nacional. Dessa forma, a Constituição aponta regramentos que devem orientar a vida das pessoas para conviverem com a diversidade presente no território nacional, o que é um ganho, pois, a partir dessa iniciativa, verifica-se um primeiro passo para a desconstrução do imaginário de 


\section{Aillbapẫ \\ 3}

ISSN: 1984-6444 | http://dx.doi.org/10.5902/1984644443774

existe nesse contexto, pois é o imigrante que terá que se reinventar para aprender a língua portuguesa, a qualquer custo, afinal, diante dessa prática, o que fica implícito é que ele deve se adequar ao ensino, já que é o maior interessado nessa aprendizagem.

\section{Considerações finais}

Vimos que o mito do monolinguismo enraizado em nossa cultura, mesmo sendo paradoxal à nossa história, tem reverberado o apagamento de memória linguística e cultural de muitas pessoas que escolhem o Brasil como morada. Por isso, (re)conhecer a legislação e as políticas linguísticas já implementadas, é um caminho para que as pessoas desenvolvam iniciativas que minimizem as diferenças e tornem a nossa sociedade mais inclusiva e democrática.

É válido ressaltar, mais uma vez, que o nosso país é multicultural e plurilinguístico, fato esse que não valida a tentativa de instituir uma única forma de ensino do português em nossas escolas. Portanto, políticas devem ser (re)pensadas como forma de diminuir as desigualdades existentes nesses cenários marcados pela ideologia de homogeneidade linguística nacional e o apagamento de identidades múltiplas.

Além da implementação de políticas, há de se pensar, para que esses obstáculos sejam superados, na formação e capacitação contínua de professores que atuam nesses locais, a fim de que esses profissionais possam analisar criticamente seu contexto de ensino/atuação e implementar práticas pedagógicas autorais que favoreçam a aprendizagem e a inclusão desses estudantes nas escolas brasileiras.

\section{Referências}

AKKARI, Abdeljalil. A agenda internacional para educação 2030: consenso "frágil" ou instrumento de mobilização dos atores da educação no século XXI, Rev. Diálogo Educ. Curitiba, v. 17, n. 53, p. 937-958, 2017. 


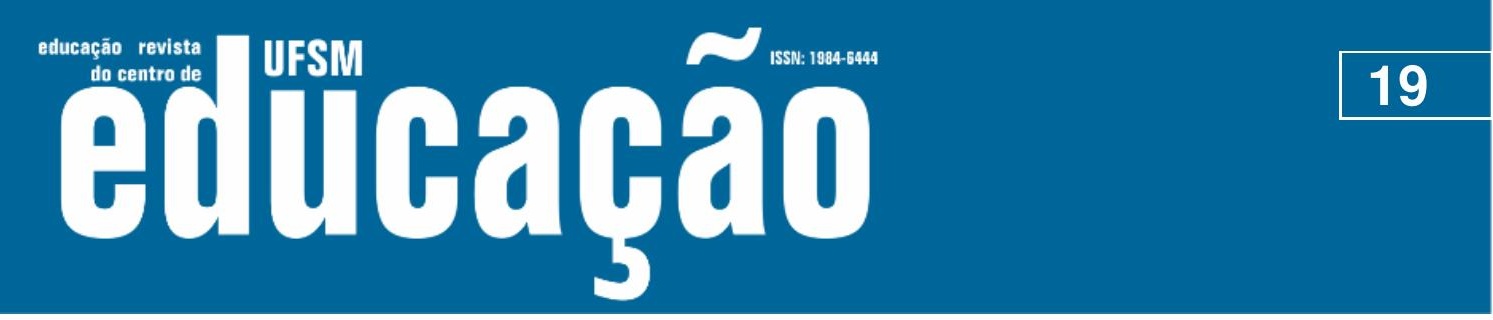

ISSN: 1984-6444 | http://dx.doi.org/10.5902/1984644443774

BAKER, Colin. Foundations of Bilingual Education and Bilingualism. 3rd edn. Multilingual Matters LTD, 2001.

BRASIL. Constituição da República Federativa do Brasil de 1988. Disponível em: http://www.planalto.gov.br/ccivil_03/constituicao/constitui\%C3\%A7a024.htm. Acesso em: 05 ago. 2018.

BRASIL. Lei de Diretrizes e Bases da Educação Nacional. Lei número 9394, 20 de dezembro de 1996.1 Disponível em: http://www.planalto.gov.br/ccivil_03/leis/L9394.htm. Acesso em: 04 ago. 2018.

BRASIL. Lei 10.436, de 24 de abril de 2002. Dispõe sobre a Língua Brasileira de Sinais - Libras. Brasília: Diário Oficial da União, 2002.

$\mathrm{BROCH}$, Ingrid Kuchenbecker. Papel da conscientização linguística para uma pedagogia do plurilinguismo nos anos iniciais da escola. Revista Digital de Políticas Linguísticas, v.4, p. $78-110,2012$.

BONASSI, M. Canta, América sem fronteiras: imigrantes latino-americanos no Brasil. São Paulo: Edições Loyola, 2000.

CALVET, Louis-Jean. As Políticas Linguísticas. Florianópolis e São Paulo: Ipol/Parábola, 2007. p. 166.

FARACO, Carlos Alberto. Norma-padrão brasileira: desembaraçando alguns nós. In: BAGNO, Marcos (Org.). Lingüística da norma. São Paulo: Loyola, 2002. p. 37- 61.

HORNBERGER, Nancy H; McKAY, Sandra Lee. Ebook (EPUB). Edição: 1, 592 pages. Multilingual Matters. 17 jun. 2010.

IBGE. Brasil tem quase 900 mil índios de 305 etnias e 274 idiomas. Mapa. Disponível em: http://www.ibge.gov.br/home/estatistica/populacao/censo2010. Acesso em: 28/09/2018.

MORELLO, Rosângela. Leis e Línguas no Brasil. O processo da cooficialização e sua pontencialidades. Florianópolis: IPOL, 2015.

OLIVEIRA, Antônio Tadeu Ribeiro de. Nova lei brasileira de migração: avanços, desafios e ameaças. Rev. bras. estud. popul. [on-line]. 2017, v. 34, n. 1 [cited 2018-06-10], pp.171-179. Disponível em: http://www.scielo.br/scielo.php?script=sci_arttext\&pid=S010230982017000100171\&lng=en\&nrm=iso. - ISSN 0102-3098. http://dx.doi.org/10.20947/s0102-3098t0010. Acesso em: 28/09/2018. 


\section{N

ISSN: 1984-6444 | http://dx.doi.org/10.5902/1984644443774

OLIVEIRA, Gilvan Müller. A cooficialização de línguas em nível municipal no Brasil: direitos linguísticos, inclusão e cidadania. In: Leis e Línguas no Brasil. O processo da cooficialização e sua pontencialidades. Florianópolis: IPOL, 2015.

SABOIA, Gillberto Vergne. O Brasil e o sistema internacional de proteção dos direitos humanos. In: JÚNIOR, Alberto do Amaral; Perrone-Moisés, Cláudia (Org.). 0 cinqüentenário da Declaração universal dos direitos do homem. EdUSP, 1999. $452 \mathrm{p}$.

SANTOS, Alessandra de Souza. Multilinguismo em Bonfim/ RR: o ensino de língua portuguesa no contexto da diversidade linguística. Tese, 2012. (Doutorado em Linguística). Universidade de Brasília, 2012.

SOUZA, Janaína Moreira Pacheco de. Representações sociais de professores de língua portuguesa e inglesa sobre o bilinguismo em escolas no município de Bonfim - fronteira Brasil/Guiana Inglesa. Dissertação (Mestrado em Educação). Universidade Estácio de Sá, 2014.

SOUZA, Janaína Moreira Pacheco de. Ser professora em área de fronteira bilíngue no Brasil: desafios e possibilidades. Tese de doutorado. Universidade do Estado do Rio de Janeiro (UERJ). 2019.

UNESCO. Marco da educação 2030: Declaração de Incheon. Incheon, Coréia do Sul: UNESCO, 2015.

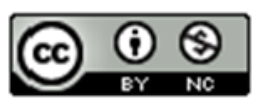

This work is licensed under a Creative Commons Attribution-NonCommercial 4.0 International (CC BY-NC 4.0) 